\title{
Association between SOX5 genotypes and semen quality in Polish Holstein-Friesian bulls
}

\author{
D.M. Hering, S. Kamiński \\ University of Warmia and Mazury in Olsztyn, \\ Department of Animal Genetics, 10-719 Olsztyn, Poland
}

\begin{abstract}
The aim of this study was to evaluate the effect of C/T missense mutation (SOX5) gene on selected parameters of non-frozen semen in Polish Holstein - Friesian bulls. Three hundred and sixty eight bulls were genotyped by the PCR-Rsa I technique. Semen was collected and evaluated by standardized procedure used in an AI station. Significant associations were found between SOX5 genotypes and sperm concentrations $(\mathrm{p}=0.020)$ and sperm motility $(\mathrm{p}=0.014)$. Bulls with TT genotype had the lowest values of both traits. Our results demonstrate that $\mathrm{C} / \mathrm{T}$ missense mutation within the SOX5 gene is involved in bull sperm quality.
\end{abstract}

Key words: bull, sperm motility, mutation, SOX5

\section{Introduction}

The SOX5 gene binds specifically to the DNA sequence and activates or represses target genes, including genes important for sperm hyperactivation, flagellar motility and maintenance of the axoneme structure of mature mammalian sperm (Budde et al. 2002, Xu et al. 2009, Kiselak et al. 2010, Mata-Rocha et al. 2014). Based on the Genome-Wise Association Study in bulls we found that the genetic marker rs29011704 located at a distance of $807214 \mathrm{bp}$ from the SOX5 gene is significantly associated with sperm motility in bulls (Hering et al. 2014). As previously noted (Kiselak et al. 2010) S-SOX5 (48-kDa SOX5 protein) plays a key role in the formation and function of motile cilia.

\section{Materials and Methods}

The analyzed data consisted of 368 Polish Holstein - Friesian bulls of the same age (12-18 months) from one AI station. All bulls included in the study had uniform feeding and housing conditions. Sperm concentration and sperm motility was assessed in fresh spermatozoa using the standard method used by the AI company. To detect the polymorphism, genomic DNA was used to genotype each bull using the PCR technique. A $381 \mathrm{bp}$ fragment of the SOX5 gene was amplified by PCR (with primers: forward 5'-TTTGCTTTGAGTCCCTGGTT-3'; reverse 5'GGGCTGTTTGTGCTCTTGTC-3') at an annealing temperature of $68^{\circ} \mathrm{C}$. Genotyping of the SOX5 missense mutation was performed using Rsa I 
Table 1. Means (0) and standard deviations (SD) for sperm quality traits in non-frozen-thawed sperm of bulls with particular SOX5 genotypes. CONC (in $\mathrm{mln} / \mathrm{ml}$ ) - sperm concentration, VOL (in ml) - semen volume, NSP (in mln) - number of spermatozoa (in total semen volume), MOT (in \%) - sperm motility.

\begin{tabular}{|c|c|c|c|c|c|c|c|c|c|}
\hline \multirow{3}{*}{ Semen trait } & \multicolumn{2}{|c|}{ All bulls (368) } & \multicolumn{6}{|c|}{ Bulls with genotypes } & \multirow{3}{*}{$p$-value } \\
\hline & \multirow{2}{*}{0} & \multirow{2}{*}{$\mathrm{SD}$} & \multicolumn{2}{|c|}{$\mathrm{CC}=50$} & \multicolumn{2}{|c|}{$\mathrm{CT}=180$} & \multicolumn{2}{|c|}{$\mathrm{TT}=138$} & \\
\hline & & & 0 & SD & 0 & SD & 0 & $\mathrm{SD}$ & \\
\hline CONC & 1305 & 399 & $1242^{\mathrm{a}}$ & 462 & $1369^{\mathrm{b}}$ & 375 & $1240^{\mathrm{a}}$ & 393 & 0.020 \\
\hline MOT & 53.9 & 16.0 & $55.8^{\mathrm{a}}$ & 14.9 & $55.9^{\mathrm{a}}$ & 15.8 & $50.4^{\mathrm{b}}$ & 16.4 & 0.014 \\
\hline VOL & 3.10 & 0.71 & 3.11 & 0.64 & 3.08 & 0.73 & 3.11 & 0.74 & 0.790 \\
\hline NSP & 4211 & 1592 & 3926 & 1558 & 4399 & 1581 & 4066 & 1599 & 0.099 \\
\hline
\end{tabular}

Means with different letter differ significantly at $\mathrm{p}<0.05$.

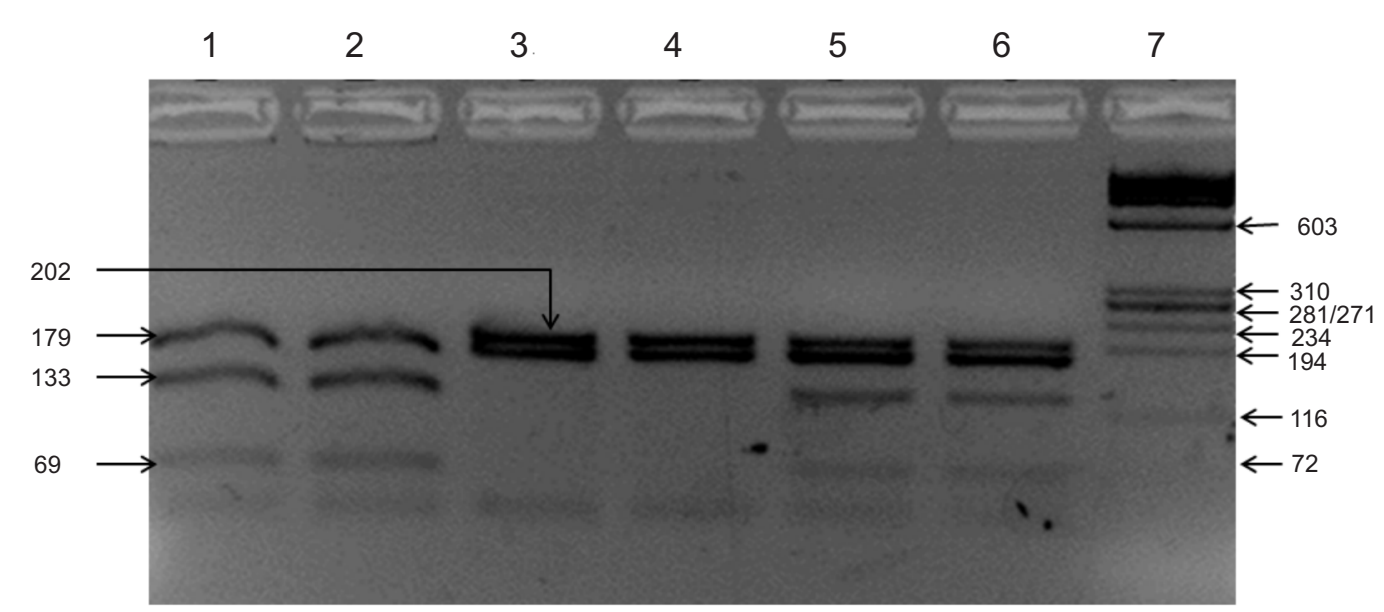

Fig. 1. Genotyping of SOX5 C/T missense mutation by RsaI restriction enzyme. Lines 1,2 - CC genotype; lines 3,4 - TT genotype; lines 5,6 - CT genotypes; line 7 - DNA size marker $\varnothing$ X174 DNA.

(5'-GTAC-3') restriction enzyme (New England BioLabs, Ipwich, MA, USA). The Kruskal-Walis test (Statistica, v.10.0) was used to find associations between SOX5 genotypes (CC, CT, TT) and selected semen traits of non-frozen semen in Polish Holstein - Friesian bulls.

\section{Results and Discussion}

Genotyping of SOX5 C/T missense mutation is illustrated in Fig. 1. In our study, significant associations were found between SOX5 genotypes and sperm motility and sperm concentration measured in non-frozen semen. Bulls with TT genotype had significantly lower values of sperm motility in comparison to bulls with CT and CC genotype. Sperm concentration significantly differed in TT and CC bulls with the lowest values of sperm concentration in comparison to
CT bulls with the highest values. SOX5 polymorphism has already been investigated as a risk factor associated with non-obstructive azoospermia (NOA) in the human (Zou et al. 2014). Tu et al. (2015) found that normozoospermic males with the risk genotypes in the PRMT6, HLA-DRA and SOX5 genes have higher sperm counts relative to non-risk genotypes. Kiselak et al (2010) indicated that the S-SOX5 participates in the formation and function of motile cilia by transcriptional regulation of an axonemal central apparatus gene, sperm - associated antigen 6 (SPAG6). Impact of SOX5 (in co-operation with SOX9) on cation channel, sperm associated 1 (CATSPER1) expression was demonstrated by Mata-Rocha et al. (2014). So far, association SOX5 polymorphism with sperm motility has not been studied. In conclusion, our results demonstrate for the first time that $\mathrm{C} / \mathrm{T}$ missense mutation within the SOX5 gene is involved in bull sperm quality. 


\section{Acknowledgments}

We are thankful to SHiUZ Bydgoszcz AI Center for delivering samples and data. Research funded by University of Warmia and Mazury grant no. 0105-0804.

\section{References}

Budde LM, Wu C, Tilman C, Douglas I, Ghosh S (2002) Regulation of IkappaBbeta expression in testis. Mol Biol Cell 13: 4179-4194.

Hering DM, Olenski K, Kamiński S (2014) Genome-wide association study for poor sperm motility in Holstein-Friesian bulls. Anim Reprod Sci 146: 89-97.

Kiselak EA, Shen X, Song J, Gude DR, Wang J, Brody SL, Strauss JF, Zhang Z (2010) Transcriptional Regulation of an Axonemal Central Apparatus Gene, Sperm - associated Antigen 6, by a SRY-related High Mobility
Group Transcription Factor, S-SOX5. J Biol Chem 285: 30496-30505.

Mata-Rocha M, Hernandez-Sanchez J, Guarneros G, de la Chesnaye E, Sanchez-Tusie AA, Trevino CL, Felix R, Oviedo N (2014) The transcription factors SOX5 and SOX9 regulate Catsper1 gene expression. FEBS Lett 588: 3352-3360.

Tu W, Liu Y, Shen Y, Yan Y, Wang X, Yang D, Li L, Ma Y, Tao D, Zhang S, Yang Y (2015) Genome-wide Loci Linked to Non-Obstructive Azoospermia Susceptibility May be independent of reduced Sperm production in Males with Normozoospermia. Biol Reprod 92 (2): 41, 1-6.

Xu W, Zhang S, Qiu W, He G, Liu Y, Sun Y, Ma Y, Dong J, Zhang W (2009) Spermatogenesis-related ring finger gene ZNF230 promoter: identification and functional analysis. Mol Biol Rep 36: 1187-1193.

Zou S, Li Z, Wang Y, Chen T, Song P, Chen J, He X, Xu P, Liang M, Luo K, Zhu X, Tian E, Du Q, Wen Z, Li Z, Wang M, Sha Y, Cao Y, Shi Y, Hu H (2014) Association Study Between Polymorphism of PRMT6, PEX10, SOX5, and Nonobstructive Azoospermia in the Han Chinese Population. Biol Reprod 90 (5): 96, 1-4. 